\title{
A preliminar study of a neuroimmune regimen with low- dose angiotensin 1-7 plus melatonin to improve the safety of covid 19 vaccine
}

Paolo Lissoni $^{*}{ }^{*}$, Franco Rovelli ${ }^{1}$, Giusy Messina ${ }^{1}$, Alejandra Monzon ${ }^{1}$, Massimo Colciago $^{2}$, Agnese Valentini ${ }^{3}$, Giuseppe Di Fede ${ }^{1}$ and Daniel Pedro Cardinali ${ }^{4}$

${ }^{1}$ Institute of Biological Medicine, Milan, Italy

${ }^{2}$ INRCA-IRCCS Institute, Casatenovo, Lecco, Italy

${ }^{3}$ Madonna del Soccorso Hospital, San Benedetto del Tronto, Ascoli Piceno, Italy

${ }^{4}$ Facultad de Medicina, Pontificia Universitad Catolica, Buenos Aires, Argentina

\begin{abstract}
In experimental conditions, it has been demonstrated that vaccine efficacy and the toxicity is depending on cytokine-induced immunoinflammatory response, and that they may be modulate through a neuroimmune approach, which neuroendocrine agents, such as the pineal hormone melatonin (MLT) and the enzymatic product of ACE2, the angiotensin 1-7 (Ang 1-7). On these bases, a preliminary study was planned to evaluate the influence of an oral peri-vaccination regimen with MLT plus Ang 1-7 on the subjective safety of Covid19 Pfizer-BioNTech (PF) and AstraZeneca (AZ) vaccines. The study included 60 subjects, 30 of whom received PF vaccine, while the other 30 subjects were treated by AZ vaccine. Both groups of subjects were randomized to receive the only vaccine or vaccine plus Ang 1-7 (0.5 mg/day in the morning) and MLT (10 mg/day in the evening) regimen, starting 3 days prior to vaccine and for the successive 4 days. The percentage of episodes of fever higher than $38^{\circ} \mathrm{C}$, asthenia and myalgia were significantly reduced by the concomitant administration of Ang 1-7 plus MLT. This preliminary study shows the possibility to modulate the safety of Covid19 vaccine through a neuroimmune approach consisting of Ang 1-7 plus MLT. Further studies will be required to confirm these data, and to evaluate the impact not only on the safety, but also on the efficacy of Covid19 vaccination..
\end{abstract}

\section{Introduction}

The dramatic planetary experience of Covid 19 infection has confused the theoretical bases of the Medical Sciences, which has appeared to be unable to understand the physiopathology of the cytokine network, whose exaggerated activation is responsible for the complications of disease and death [1]. IL-17 would be the main inflammatory cytokine involved in Covid 19 disease [2], because of its thrombotic properties and cytotoxic action for both lung and heart [3]. The link of viral spike protein to ACE2 receptor induces a downregulation of ACE2 expression, with a following acute and severe deficiency of its enzymatic product, the angiotensin 1-7 (Ang 1-7) [4], which exerts opposite effects with respect to those played by angiotensin II (Ang II). In fact, Ang II has been proven to exert hypertensive, inflammatory, angiogenic, pro-tumoral, pro-thrombotic and pro-fibrotic effects, whereas Ang 1-7 plays hypotensive, antiinflammatory, anti-angiogenic,anti-tumoral, anti-thrombotic and anti-fibroticeffects [5]. Moreover, it has been shown that IL-17 may stimulate ACE expression and inhibit that of ACE2 [6], by furtherly worsening Ang 1-7 deficiency. Most cytokines of the cytokine network play a pro-inflammatory action [7], and only few cytokines exert an anti-inflammatory action, including IL-10, TGF-beta, IL-21, IL-30, IL35, and IL-37. Moreover, the anti-inflammatory action of IL-10, TGFbeta and IL-35 is associated with a concomitant immunosuppressive activity. Therefore, in physiological conditions, the anti-inflammatory control is mainly played by a neuroendocrine axis constituted of the pineal gland, whose main hormone is melatonin (MLT) [8-10], the cannabinoid system [11], and Ang 1-7 [12], which are all characterized by an anticancer activity and an inhibitory action on the secretion of IL-17 and macrophage-related cytokines, including IL-1beta, IL-6 and TNF-alpha. The immunomodulating properties of both MLT and Ang 1-7 are also confirmed by the expression of receptors for MLT and Ang 1-7 by the various immune cells $[8,13]$. Macrophages would mainly express Ang 1-7 receptors [13], while lymphocytes mainly express MLT receptors [8]. An anti-inflammatory action is also played by alpha-MSH [14] and by the adrenal gland trough the release of cortisol [15], which, however, exert a concomitantimmunosuppressive effect [14]. As far as Covid 19 vaccine is concerned, it is known that all vaccinations require an adequate function of the immune cells to be effective, including the dendritic cells because of their function as antigen presenting cells, whose activity has appeared to be enhanced by MLT, which has also been proven to stimulate IL-2 secretion from Th1 cells [8-10]. Finally, it is known that the possible side-effects of the vaccination, including fever, myalgia, asthenia, headache, are due to a transient enhanced endogenous production of inflammatory cytokines concomitantly to the activation of an effective immune response. Moreover, in the case of Covid 19 vaccine, the action of the spike

${ }^{*}$ Correspondence to: Paolo Lissoni, Institute of Biological Medicine, Milan, Italy, E-mail: paolo.lissoni@gmx.com

Key words: Angiotensin 1-7, covid 19, covid19 vaccine, melatonin, neuroimmunomodulation

Received: May 10, 2021; Accepted: June 07, 2021; Published: June 10, 2021 
protein could determine a transient endogenous Ang 1-7 deficiency due to its interaction with ACE2 receptor.Therefore, a short-time preparation with neuroendocrine anti-inflammatory agents, such as low-dose MLT and Ang 1-7 itself, could better improve the safety of vaccination, because of their inhibitory action on the secretion of IL17, IL-6, and TNF-alpha [8-12]. Therefore, the potential therapeutic role of both MLT and Ang 1-7 in the treatment of Covid 19 infection is also suggested by the fact that Covid 19 infected patients under chronic treatment with MLT for different reasons may present a better prognosis with less complications [16], as well as by the fact that all patients at higher risk for disease complications, including male aged subjects and those with hypertension, obesity and diabetes mellitus, are characterized by a diminished ACE2 expression and a consequent diminished Ang 1-7 endogenous production [17]. Finally, MLT has been proven to counteract ACE expression and stimulate that of ACE2, by enhancing Ang 1-7 secretion [18]. On these bases, a preliminary study was planned to evaluate the influence of a neuroendocrine regimen with low-dose MLT plus Ang 1-7 administered for some days prior and after BNT162b2 mRNA (Pfizer-BioNTech) (PF) [19] or Oxford-AstraZeneca (AZ) Covid19 vaccine [20].

\section{Subjects and Methods}

The study included 60 consecutive healthy subjects. According to the dispositions of the Healthy Ministry in relation to several variables, including age and sex, 30 of whom received PF Covid-19 vaccine, while the other 30 patients were treated by AZ Covid-19 vaccine. After the approval of the Ethical Committee, the clinical protocol was explained to each patient, and written consent was obtained. Both groups of subjects were randomized to receive vaccine alone or vaccine in association with a neuroendocrine peri-vaccination regimen of MLT plus Ang 1-7. Both vaccines consisted of two injections at 21-day interval for $\mathrm{PF}$ vaccine and after 3 months for $\mathrm{AZ}$ vaccine. Because of the apparent more pronounced side-effects after the second injection of PF vaccine and after the first dose for $A Z$ vaccine $[19,20]$, the study was limited to the evaluation of the effects of both $P F$ vaccine injections, and only after the first $\mathrm{AZ}$ vaccine administration. In both groups of subjects, MLT was given orally at $10 \mathrm{mg} /$ day during the dark period of the day. Ang 1-7 also was given orally in gastro-protected capsules at a dose of $0.5 \mathrm{mg} /$ day in the morning. The treatment was started 3 days before vaccination, and it was continued for other 4 days after vaccine injection. The following symptoms were considered: feverless than $38^{\circ} \mathrm{C}$, fever higher than $38^{\circ} \mathrm{C}$, myalgia, asthenia, headache, loss of taste, nausea, vomiting, diarrhoea, pain at site of injection, thrombosis, allergy, and cardiovascular complications. Data were statistically analysed by the chi-square test.

\section{Results}

The characteristics of subjects and their reactions to $\mathrm{PF}$ or $\mathrm{AZ}$ vaccine are reported in Table 1 and in Table 2, respectively. As shown in the Table 1, cardiovascular complications, thrombosis, and allergy events occurred in no subject of both groups treated by PF vaccine. Moreover, taken together, both groups of subjects referred a better safety after the first vaccine injection with respect to the second one. The concomitant preparation with MLT and Ang 1-7 improved the safety of vaccine. In more detail, the percentage of episodes of fever higher than $38^{\circ} \mathrm{C}$, myalgia, and asthenia observed in subjects who received the only $\mathrm{PF}$ vaccine was significantly greater than that found in subjects concomitantly treated with MLT plus Ang 1-7 $(\mathrm{P}<0.05)$. As far as AZvaccine is concerned, as shown in Table 2, the peri-vaccination treatment with MLT and Ang 1-7 statistically significantly reduced the
Table 1. Characteristics of subjects who received the only Covid 19 Pfizer-BioNTech vaccine as a control group $(\mathrm{n}=16 ; \mathrm{M} / \mathrm{F}$ : 7/9; median age 55 years, range 28-72) or vaccine plus melatonin (MLT) and angiotensin 1-7 (Ang 1-7) (n=14; M/F: 6/8; median age 58 years, range 20-74), and their side effects

\begin{tabular}{|c|c|c|c|c|}
\hline \multirow[t]{2}{*}{ Symptoms } & \multicolumn{2}{|c|}{ Controls $(n=16)$} & \multicolumn{2}{|c|}{$\begin{array}{l}\text { MLT plus Ang 1-7 } \\
(\mathrm{n}=14)\end{array}$} \\
\hline & $1^{\text {st }}$ DOSE & $2^{\text {nd }}$ DOSE & $1^{\text {st }}$ DOSE & $2^{\text {nd }}$ DOSE \\
\hline Fever Less Than $38^{\circ} \mathrm{C}$ & $4(25 \%)$ & $7(44 \%)$ & $3(21 \%)$ & $4(29 \%)$ \\
\hline Fever More Than $38^{\circ} \mathrm{C}$ & $3(19 \%)$ & $6(38 \%)^{*}$ & $1(7 \%)$ & $2(14 \%)$ \\
\hline Myalgia & $4(25 \%)$ & $5(31 \%)^{*}$ & 0 & $1(7 \%)$ \\
\hline Asthenia & $4(25 \%)$ & $6(38 \%)^{*}$ & $1(7 \%)$ & $2(14 \%)$ \\
\hline Taste Loss & $2(13 \%)$ & 0 & $1(7 \%)$ & 0 \\
\hline Pain At Injection Site & $5(32 \%)$ & $8(50 \%)$ & $2(14 \%)$ & $4(28 \%)$ \\
\hline Headache & $2(12 \%)$ & $4(25 \%)$ & $1(7 \%)$ & $2(14 \%)$ \\
\hline Nausea & $2(12 \%)$ & $3(19 \%)$ & 0 & $2(14 \%)$ \\
\hline Vomiting & $1(6 \%)$ & 0 & 0 & 0 \\
\hline Diarrhoea & $1(6 \%)$ & 0 & 0 & 0 \\
\hline Thrombosis & 0 & 0 & 0 & 0 \\
\hline Cardiovascular Complications & 0 & 0 & 0 & 0 \\
\hline Allergy & 0 & 0 & 0 & 0 \\
\hline
\end{tabular}

Table 2. Characteristics of subjects who received the only Covid 19 AstraZeneca as a control group $(\mathrm{n}=15 ; \mathrm{M} / \mathrm{F}$ : 7/8; median age 41 years, range $31-54)$ or vaccine plus melatonin (MLT) and angiotensin 1-7 (Ang 1-7) (n=15; M/F: 6/9; median age: 42 years, range 32-53), and their side-effects

\begin{tabular}{|l|c|c|}
\hline Symptoms & Controls (n=15) & $\begin{array}{c}\text { MLT plus Ang 1-7 } \\
(\mathbf{n}=\mathbf{1 5})\end{array}$ \\
\hline Fever Less Than $38^{\circ} \mathrm{C}$ & $5(33 \%)$ & $3(20 \%)$ \\
\hline Fever More Than $38^{\circ} \mathrm{C}$ & $3(20 \%)^{* *}$ & 0 \\
\hline Myalgia & $4(27 \%)^{*}$ & $1(7 \%)$ \\
\hline Asthenia & $6(40 \%)^{*}$ & $2(13 \%)$ \\
\hline Taste Loss & $1(7 \%)$ & 0 \\
\hline Pain At Injection Site & $4(27 \%)$ & $3(20 \%)$ \\
\hline Headache & $2(13 \%)$ & 0 \\
\hline Nausea & $2(13 \%)$ & 0 \\
\hline Vomiting & $1(7 \%)$ & 0 \\
\hline Diarrhoea & $1(7 \%)$ & 0 \\
\hline Thrombosis & 0 & 0 \\
\hline Cardiovascular Complications & 0 & 0 \\
\hline Allergy & 0 & \\
\hline$*$ P $<0.05$ vs MLT plus Ang $1-7 ; * * P<0.01$ vs MLT plus Ang $1-7$. & \\
\hline
\end{tabular}

percentage of episodes of fever higher than $38^{\circ} \mathrm{C}$, asthenia, and myalgia $(\mathrm{P}<0.05)$. No important decline in blood pressure values was observed under Ang 1-7 administration in both groups of subjects treated by PF or $\mathrm{AZ}$ vaccine. On the contrary, two hypertensive subjects experienced a normalization of blood pressure on Ang 1-7 treatment.

\section{Discussion}

The results of this preliminary study would suggest that the already low side-effects of both PF and AZ Covid-19 vaccines may be furtherly reduced by a short peri-vaccinal treatment with anti-inflammatory neuroendocrine agents, such as the pineal hormone MLT and Ang 1-7. Then, these results would confirm the previous proposals of other authors [4], which in experimental conditions had already demonstrated that both Ang 1-7 [4] and MLT [21,22] may modulate viral infectioninduced inflammatory response. The importance of these preliminary results could be more important from a psychological and social point of view rather than the medical one, because of the great social confusion concerning both Covid19 disease and Covid 19 vaccination, which is due to the ambiguous news of the social communication. In more detail, as far as the possible connection between Covid19 vaccine and 
thrombotic events, particularly in the case of AZ vaccine, which in any case has been already excluded by the scientific authorities, at least from a theoretical point of view, it is possible to hypothesize the occurrence of a transient spike protein-induced endothelia damage, with a following predisposition to thrombotic events. In any case, this theoretical risk could be completely abrogated by a concomitant administration of Ang 1-7 because of its fundamental anti-thrombotic activity [4], and whose deficiency could constitute the main pathogenetic event responsible for the clinical complications of Covid19 disease [1].

\section{References}

1. Lissoni P, Rovelli F, Monzon A, Messina G, Porta E, et al. (2020) COVID-19 diseaseas an acute angiotensin 1-7 deficiency: a preliminaryphase 2 study with angiotensin 1-7 in association with melatonin and cannabidiol in symptomatic COVID-19 infectedsubjecs. J Infectiology 3: 13-16.

2. Megna M, Napolitano M, Fabbrocini G (2020) May IL-17 have a role in COVID-19 infection? Med Hypotheses 140: 109749. [Crossref]

3. Robert M, Miossec P (2017) Effects of interleukin17on the cardiovascular system. Autoimmun Rev 16: 984-991. [Crossref]

4. Simoes-e-Silva AC, Silveira KD, Ferreira AJ, Teixeira MM (2013) ACE2, angiotensin-(1-7) and Mas receptor axis in inflammation and fibrosis. Br J Pharmacol 169: 477-492. [Crossref]

5. Cheng H, Wang GQ (2020) Organ-protective effect of angiotensin-converting enzyme 2 and its effects on the prognosis of COVID-19. J Med Virol 92: 726-730. [Crossref]

6. Madhur MS, Lob HE, McCann LA, Iwakura Y, Blinder Y, et al. (2010) Interleukin 17 promotes angiotensin II-induced hypertension and vascular dysfunction. Hypertensin 554: 500-507. [Crossref]

7. Lissoni P, Messina G, Pelizzoni F, Rovelli F, Brivio F, et al. (2020) The fascination of cytokineimmunological science. J Infectiology 3: 18-28.

8. Maestroni GJM (1993) The immunoneuroendocrine role of melatonin. J Pineal Res 14: 1-10. [Crossref]
9. Lissoni P (1999) The pineal gland as acentralregulatorof cytokine network. Neuro Endocrinol Lett 20: 343-349. [Crossref]

10. Kuklina EM, Glebezdina NS, Nekrasova IV (2016) Role of melatonin in the regulation of differentiation of T cells producing interkeukin-17 (Th17). Bull Exp Med Med 160: 656658. [Crossref]

11. Grotenhermen F (2004) Pharmacology of cannabinoids. Neuroendorinol Lett 25: 14-23. [Crossref]

12. Platten M, Youssef S, Hur EM, Ho PP, Han MH, et al. (2009) Blocking angiotensinconverting enzyme induces potent regulatory $\mathrm{T}$ cells and modulates TH1- and TH17mediated autoimmunity. Proc Natl Acad Sci USA 106: 14948-14953. [Crossref]

13. Song X, Hu W, Yu H, Zhao L, Zhao Y, et al. (2020) Little to no expression of angiotensinconverting enzyme- 2 on most human peripheral blood immune cells but highly expressed on issue macrophages. Cytometry A. [Crossref]

14. Baldini G, Phelan KD (2019) The melanocortin pathways an control ofappetite: progress and therapeutic implications. J Endocrinol 241: R1-R33. [Crossref]

15. Clamam HN (1998) Corticosteroids and the immune system. Exp Med Biol 245: 203-208.

16. Ramlall V, Zucker J, Tatonetti N (2020) Melatonin is significantly associated with survival of intubated COVID-19 patients. medRxiv. [Crossref]

17. Rodriguez-Prestes TR, Pessoa Rocha N, MrandaAS, TeixeiraAL, Simoes-e-Silva AC (2017) The anti-inflammatory potential of ACE2/angiotensin-(1-7)/Mas receptor axis: evidence from basic and clinical research. Curr Drug Targets 18: 1301-1313. [Crossref]

18. Campos LA, Cipolla-Neto J, Amaral FG, Michelini LC, Bader M, et al. (2013) The angiotensin-melatoninaxis. Int J Hypertens 2013: 521783. [Crossref]

19. Polack F, Thomas SJ, Kitchin N, Absalon J, Gurtman A, et al. (2020) Safety and efficacy of the BNT162b2 mRNA Covid-19. N Engl J Med 383: 2603-2615. [Crossref]

20. Knoll MD, Wonodi C (2021) Oxford-AstraZeneca COVID-19 vaccine efficacy. Lancet 397: 72-74.

21. ReiterRJ, Ma Q, Sharma R (2020) Treatment of Ebola and other infectious diseases: melatonin "goes viral". Melatonin Res 3: 43-57.

22. Cardinali DP, Brown GM, Pandi-Perumal SR (2021) An urgent proposal for the immediate use ofmelatonin as an adjuvant to anti-SARS-CoV-2 vaccination. Melatonin Res 4: 206-212.

Copyright: (C2021 Lissoni P. This is an open-access article distributed under the terms of the Creative Commons Attribution License, which permits unrestricted use, distribution, and reproduction in any medium, provided the original author and source are credited. 